\title{
Power-Factor and Torque Calculation with Consideration of Cross Saturation of the Interior Permanent Magnet Synchronous Motor with Brushless Field Excitation
}

\author{
Seong Taek Lee ${ }^{1,2}$, Timothy A. Burress ${ }^{1}$, Leon M. Tolbert ${ }^{1,2}$ \\ ${ }^{1}$ Oak Ridge National Laboratory \\ 2360 Cherahala Boulevard \\ Knoxville, TN 37932, USA \\ 2 Department of Electrical and Computer Engineering
The University of Tennessee
Knoxville, TN 37996, USA
}

\begin{abstract}
This paper introduces a new method for calculating the power factor and output torque by considering the cross saturation between direct-axis (d-axis) and quadrature-axis (q-axis) of an interior permanent magnet synchronous motor (IPMSM). The conventional two-axis IPMSM model is modified to include the cross saturation effect by adding the cross-coupled inductance terms. This paper also contains the new method of calculating the cross-coupled inductance values as well as self-inductance values in $d-$ and $q-$ axes. The analyzed motor is a high-speed brushless field excitation machine that offers high torque per ampere per core length at low speed and weakened flux at high speed, which was developed for the traction motor of a hybrid electric vehicle.
\end{abstract}

\section{INTRODUCTION}

The interior permanent magnet synchronous motor (IPMSM) is currently used by many leading auto manufacturers for hybrid vehicles because the power density for this type of motor is high compared with that of induction motors and switched reluctance motors.

Usually the basis of an IPMSM motor control system is the two-axis model, direct-axis (d-axis) and quadrature-axis (qaxis) [1-4]. In addition, the performance of the motor, such as output torque and power factor, depends on its two-axis inductances, $L_{d}$ and $L_{q}[1-3]$. Therefore, calculation of the exact values of the inductances is very important for successful fulfillment of expectations for the dynamic characteristics of the designed motor.

The inductance values of the $\mathrm{d}$ - and q-axes are not constant. These values vary nonlinearly under different operating conditions because the magnitude and phase angle of input current can change the magnetic flux distributions and the saturation of soft magnetic materials in the motor can change the machine reluctance [5-7].

Moreover, for development of a dynamic model of an IPMSM, cross saturation between d- and q-axes must be considered, especially for a highly saturated machine [6-11].

This paper presents the calculation method of the power factor and output torque with consideration of cross saturation. Finite element analysis (FEA) is used to obtain the flux-linkage values at the various operating conditions. The analyzed motor is an IPMSM with brushless field excitation (BFE), which was developed for application in a hybrid electric vehicle. The BFE structure enables the motor to control the magnitude of the air-gap flux, enhanced by increasing DC current to a fixed excitation coil for high torque and weakened by reducing the excitation current for high-speed operation $[12,13]$. Therefore, this paper shows the analysis results compared between the highest and the lowest excited conditions.

\section{MATHEMATICAL EQUATIONS OF IPMSM}

Below is the well-known electromagnetic torque equation for all synchronous machines:

$$
T=\frac{3}{2} p\left(\lambda_{d} i_{q}-\lambda_{q} i_{d}\right)
$$

In (1), $p$ is the number of pole pairs, $\lambda$ is the flux linkage, and $i$ is the instantaneous current. The subscripts $d$ and $q$ indicate the d-axis and q-axis, respectively. In general, the flux linkages depend on both current components $i_{d}$ and $i_{q}$, such that

$$
\lambda_{d}=\lambda_{d}\left(i_{d}, i_{q}\right), \lambda_{q}=\lambda_{q}\left(i_{d}, i_{q}\right)
$$

In the case of the classical IPMSM with sine-distributed windings and no saturation, the $\mathrm{d}$ - and $\mathrm{q}$-axis inductances can be represented by simple mathematical terms [7]:

$$
\begin{aligned}
& \lambda_{d}\left(i_{d}\right)=\lambda_{d, P M}+L_{d} i_{d} \\
& \lambda_{q}\left(i_{q}\right)=\lambda_{q, P M}+L_{q} i_{q}
\end{aligned}
$$

where $\lambda_{d, P M}$ and $\lambda_{q, P M}$ are the d- and q-axis flux linkages by the rotor flux (usually from permanent magnets), respectively.

However, the classical equation, (3), is not sufficient for developing the sophisticated dynamic model of IPMSM for either voltage-driven or current-driven control strategies, especially if the IPMSM is operated with high torque [6-11].

\footnotetext{
*The submitted manuscript has been authored by a contractor of the U. S. Government under contract no. DE-AC05-00OR22725. Accordingly, the U.S. Government retains a nonexclusive, royalty-free license to publish or reproduce the published form of this contribution, or allow others to do so, for U. S. Government purposes. Research sponsored by the Oak Ridge National Laboratory managed by UT-Battelle, LLC for the U. S. Department of Energy under contract DE-AC05-00OR22725.
} 


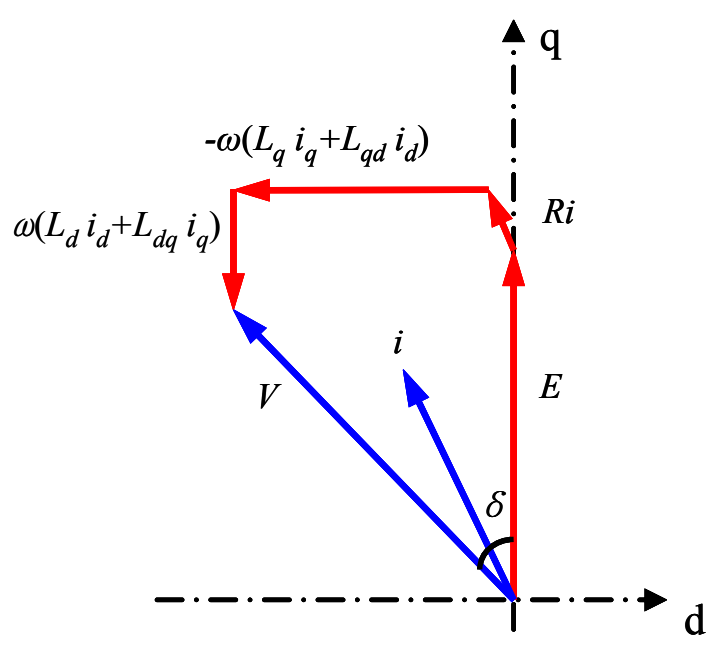

Fig. 1. Steady-state phasor diagram of IPMSM.

Below are the nonlinear flux linkage terms for a saturated IPMSM [6, 9-11]:

$$
\begin{aligned}
& \lambda_{d}\left(i_{d}, i_{q}\right)=\lambda_{d, P M}+L_{d}\left(i_{d}, i_{q}\right) i_{d}+L_{d q}\left(i_{d}, i_{q}\right) i_{q} \\
& \lambda_{q}\left(i_{d}, i_{q}\right)=\lambda_{q, P M}+L_{q}\left(i_{d}, i_{q}\right) i_{q}+L_{q d}\left(i_{d}, i_{q}\right) i_{d}
\end{aligned}
$$

Using (4), the torque in (1) is expressed as

$$
\begin{aligned}
T= & \frac{3}{2} p\left(\lambda_{d, P M} i_{q}-\lambda_{q, P M} i_{d}+\right. \\
& \left.\left(L_{d}-L_{q}\right) i_{d} i_{q}+L_{d q} i_{q}^{2}-L_{q d} i_{d}^{2}\right)
\end{aligned}
$$

The first two terms in (5) relate to the PM torque, the third relates to the reluctance torque, and the rest are from cross saturation. Considering cross saturation and assuming that $\lambda_{q, P M}$ is relatively small in the sine-distributed winding machine, the steady-state voltage equations of the IPMSM at the speed $\omega$ are

$$
\begin{aligned}
& V_{d}=R i_{d}-\omega L_{q} i_{q}-\omega L_{q d} i_{d} \\
& V_{q}=R i_{q}+\omega L_{d} i_{d}+\omega L_{d q} i_{q}+E
\end{aligned}
$$

In (6), $E$ is the back-electromotive force (back-emf) at the speed $\omega$. Fig. 1 shows the phasor diagram for the steady state based on (6).

\section{ANALYSIS MEthoD}

First, the calculation of d-axis flux linkage is carried out without current load using the FEA calculation. Then the calculation works are processed with the variation of current loading, and d- and q-axis flux linkages are obtained. When calculating the values of flux linkage, it is necessary to average the values along the angle of the rotor position over one electrical cycle [7], especially if the IPMSM has uneven air-gap flux.

After obtaining the whole range of $\lambda_{d}\left(i_{d}, i_{q}\right)$ and $\lambda_{q}\left(i_{d}, i_{q}\right)$ values, the inductances of cross-saturation terms can be determined by numerical approximation as follows:

$$
\begin{aligned}
& L_{d q}\left(i_{d}, i_{q}\right)=\left.\frac{\Delta \lambda_{d}}{\Delta i_{q}}\right|_{i_{d}=\text { constant }} \\
& L_{q d}\left(i_{d}, i_{q}\right)=\left.\frac{\Delta \lambda_{q}}{\Delta i_{d}}\right|_{i_{q}=\text { constant }}
\end{aligned}
$$

To obtain these cross-coupled inductance values, this research uses the flux linkage variation over the current variation with the span of $3 \mathrm{~A}$ in each $\mathrm{d}$ - and q-axis direction. Using an approximation function of flux linkage as suggested in [6] to reduce the simulation works may be a good method. However, to determine the self-inductance, using the direct derivatives of the approximation function as in [6] could result in very low value of q-axis inductance when the q-axis flux path is saturated.

If the calculated results are then put in (4), the values of the self-inductance for the two axes are

$$
\begin{aligned}
& L_{d}\left(i_{d}, i_{q}\right)=\frac{\lambda_{d}\left(i_{d}, i_{q}\right)-\lambda_{d, P M}-L_{d q}\left(i_{d}, i_{q}\right) i_{q}}{i_{d}} \\
& L_{q}\left(i_{d}, i_{q}\right)=\frac{\lambda_{q}\left(i_{d}, i_{q}\right)-\lambda_{q, P M}-L_{q d}\left(i_{d}, i_{q}\right) i_{d}}{i_{q}}
\end{aligned}
$$

The back-emf voltage can be obtained from the time derivative of the flux linkage waveform such that

$$
E=-\frac{d \psi}{d t}=-\frac{d \psi}{d \theta} \frac{d \theta}{d t}=-\omega \frac{d \psi}{d \theta}
$$

Using the rms value from (9), the phase voltage can be obtained from (6), as can the torque angle $\delta$. Then, the expected power factor is determined by the angle between the given current vector and the calculated voltage vector.

\section{Prototype Motor}

The assembled prototype of the Oak Ridge National Laboratory (ORNL) 16,000-rpm motor design is shown in Fig. 2. Table I compares the dimensions of the ORNL 16,000-rpm motor with those of a Toyota Prius motor that was selected as a baseline motor.

The ORNL motor has a unique side-PM structure and side-field excitation coils that produce axial flux. This flux 


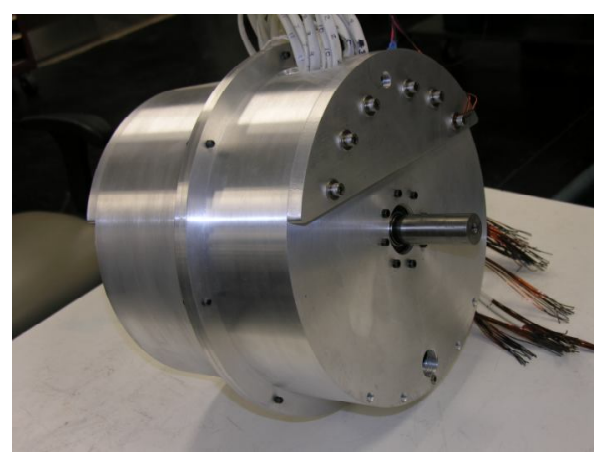

Fig. 2. Assembly of ORNL 16,000-rpm motor.

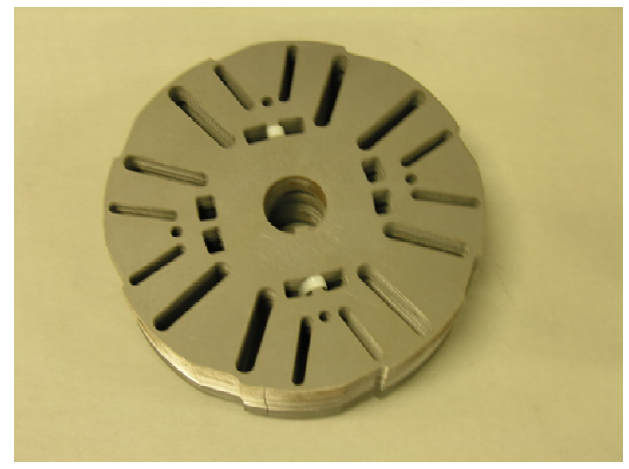

Fig. 3. Stacked rotor punching of ORNL 16,000-rpm motor.

is added to the main flux from the PMs inside the rotor and interacts with the stator current to produce motor torque. It also has an asymmetrical air gap between the north and south poles, as shown in Fig. 3. The details are presented in [12], [13], and [14].

In this paper, the comparison between simulation and test results is performed using the case of the highest and the lowest side-field excitation. When the machine is in higher excited condition, it will get higher rotor flux by adding the flux generated from its side-field excitation coils. Therefore, in the condition of the highest excitation (the excitation current is $5 \mathrm{~A}$ ), the machine could be more saturated than in the lowest excited condition (the excitation current is $0 \mathrm{~A}$ ), and then, the cross saturation effects were also different.

TABLE I

COMPARISON OF DIMENSIONS OF THE ORNL 16,000-RPM MOTOR AND THE BASELINE MOTOR

\begin{tabular}{|l|l|l|}
\hline & Prius & ORNL \\
\hline Speed & $6,000 \mathrm{rpm}$ & $16,000 \mathrm{rpm}$ \\
Stator lamination outer diameter & $269.2 \mathrm{~mm}$ & $269.2 \mathrm{~mm}$ \\
Rotor outer diameter & $160 \mathrm{~mm}$ & $160 \mathrm{~mm}$ \\
Core length & $83.82 \mathrm{~mm}$ & $47.75 \mathrm{~mm}$ \\
Bearing to bearing outer face & $196.85 \mathrm{~mm}$ & $189.23 \mathrm{~mm}$ \\
Magnet weight & $1.25 \mathrm{~kg}$ & $1.16 \mathrm{~kg}$ \\
Estimated field adj. ratio & none & 2.5 \\
Rating & $33 / 50 \mathrm{~kW}$ & $33 / 50 \mathrm{~kW}$ \\
Boost converter & yes & no \\
High-speed core loss & high & low \\
\hline
\end{tabular}

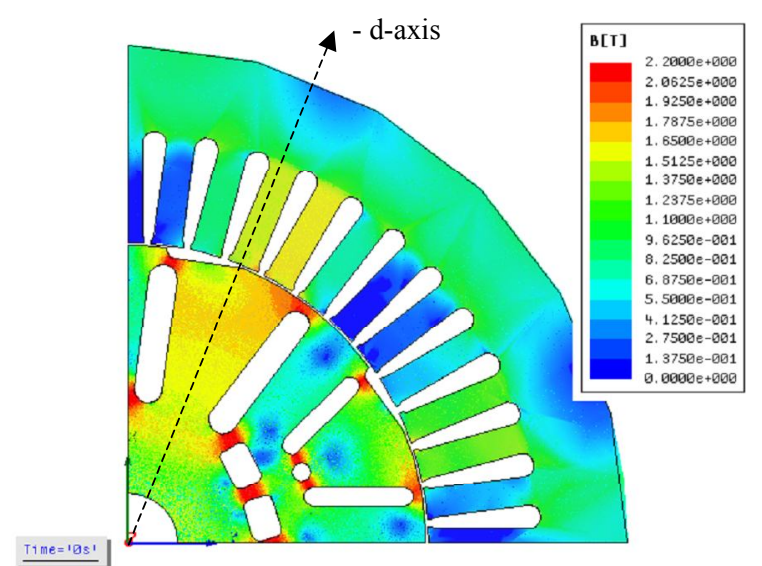

Fig. 4. Flux density distributions on rotor and stator without phase current in case of the highest excited condition.

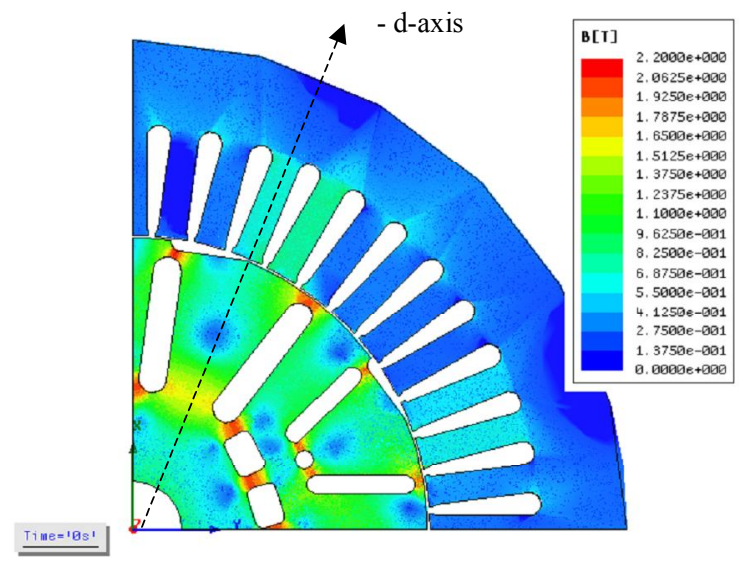

Fig. 5. Flux density distributions on rotor and stator without phase current in case of the lowest excited condition.

\section{ANALYSIS RESULtS}

\section{A. Inductance Computations}

Figs. 4 and 5 shows the FEA results of the flux density distribution on rotor and stator without phase current in two different excited conditions. In the lowest excited condition (Fig. 5), the flux density is clearly lower than in the highest excited condition, especially on the -d-axis of the rotor. These figures prove that the excited structure works well.

Figs. 6 and 7 show the variation of the flux linkage in each d- and q-axis direction at different input current conditions, from 0 to $150 \mathrm{~A}$ with a step of $30 \mathrm{~A}$ in each direction. However, d-axis current has a negative value for motoring operation in Fig. 1. As shown in these figures, the variation of the flux linkage differs by the current change in the other axis, which causes the cross saturation between the two axes. As expected, in the case of the lowest excited condition both $\mathrm{d}$-axis and q-axis flux linkage have wider variation by the change of either d-or q-axis current.

This means that the lowest excited condition has higher self-inductance values on both axes than the highest excited condition. In other words, the flux caused from stator 


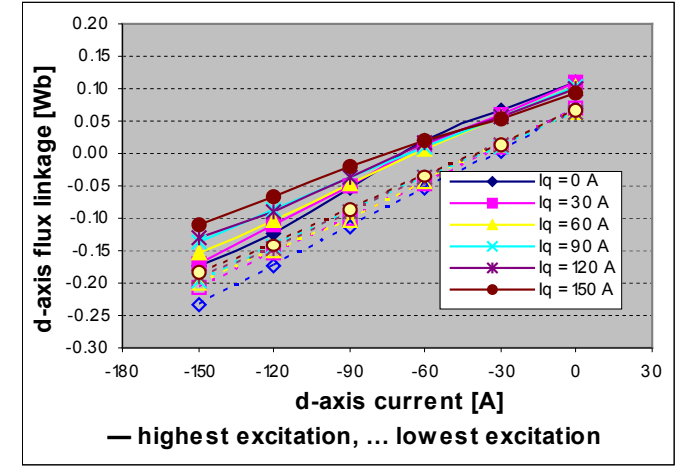

Fig. 6. d-axis flux linkage vs. d-axis current.

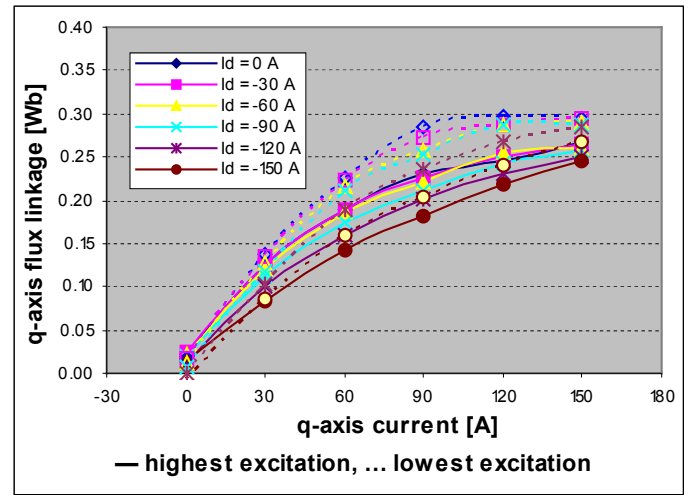

Fig. 7. q-axis flux linkage vs. q-axis current.

current can travel easily when the machine is operated at lower excited condition.

Figs. 8 and 9 present the calculated results of crosscoupled inductance using (7). $L_{q d}$ is easily influenced by daxis current before the saturation, while $L_{d q}$ is not much changed by the variation of q-axis current but $L_{d q}$ increases by increasing negative d-axis current. One note of interest from Fig. 8 is that $L_{q d}$ increases by increasing q-axis current until $I_{q}=90 \mathrm{~A}$, then it decreases with increasing q-axis current. Further research works are necessary to explain this.

Both cross-coupled inductances are determined by mainly d-axis current rather than q-axis current. The overall values of the cross-coupled inductances $L_{q d}$ with the lowest excited condition are much higher than with the highest excited condition, but the values of $L_{d q}$ are a little higher. These results suggest that $d$ - and q-axis have common magnetic flux path through the brushless field excitation structure of the machine, and it causes a small reluctance torque.

At the lowest excitation, the maximum values of either $L_{q d}$ or $L_{d q}$ reaches to about $0.6 \mathrm{mH}$ when d-axis current is $-150 \mathrm{~A}$. This value is more than $30 \%$ of the calculated self d-axis inductance. These figures also show results for $L_{d q} \neq$ $L_{q d}$ as reported in [6].

Figs. 10 and 11 show the computed self-inductances in each direction. At low q-axis current, the values of q-axis inductance are increased by negative d-axis current loading,

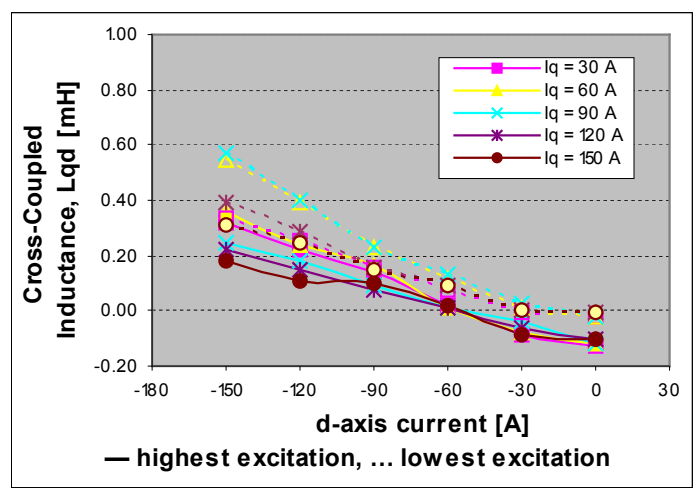

Fig. 8. Cross-coupled inductance $L_{q d}$ vs. d-axis current.

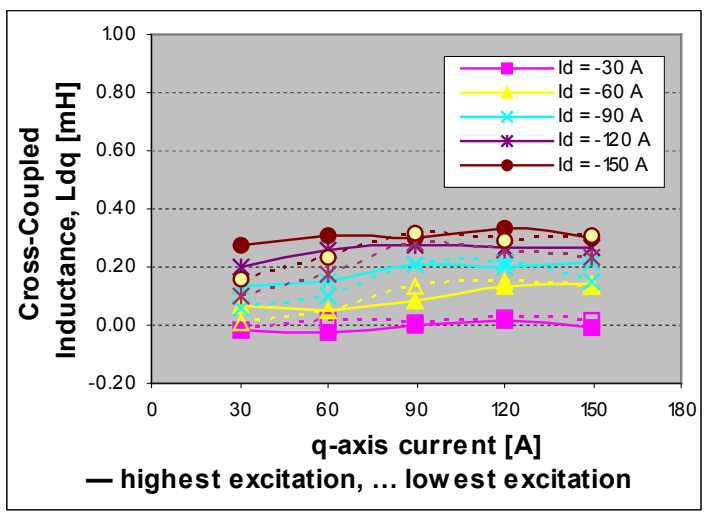

Fig. 9. Cross-coupled inductance $L_{d q}$ vs. q-axis current.

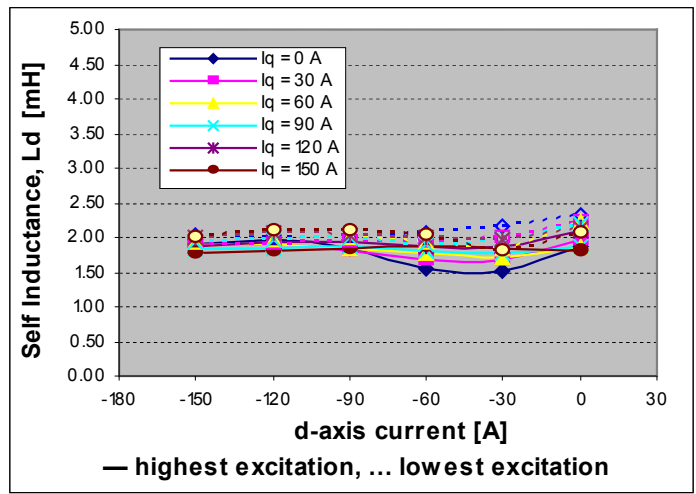

Fig. 10. Self inductance $L_{d}$ vs. d-axis current.

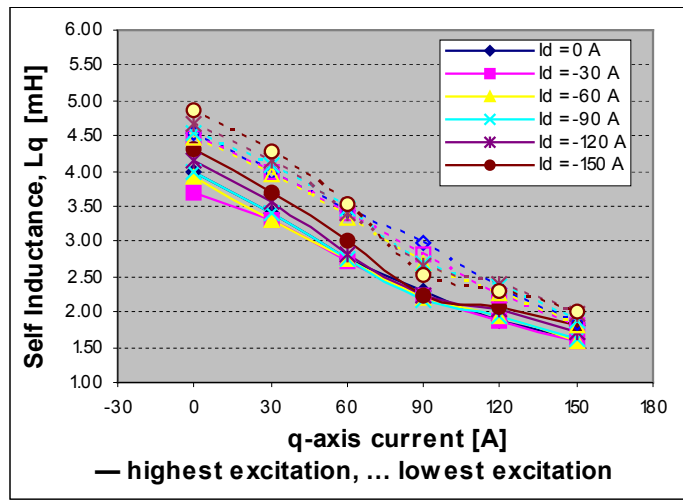

Fig. 11. Self inductance $L_{q}$ vs. q-axis current. 
as shown in Fig. 11. These results suggest that the magnetic flux from negative d-axis current is depressed by the rotor flux and goes through the q-axis flux path, especially under low q-axis current, and these results agree with the higher values of $L_{q d}$ at the lowest excited condition.

\section{B. Power Factor and Torque Computations}

Fig. 12 shows the back-emf waveform obtained from a no-load flux linkage waveform and (9) at the highest excited condition. Its fundamental is also displayed. Fig. 13 presents the line-to-neutral $\mathrm{rms}$ voltages $\left(\mathrm{V}_{\mathrm{rms}}\right)$ measured at 1000 rpm. At $5000 \mathrm{rpm}$, the expected back-emf voltage is 197.2 $\mathrm{V}_{\mathrm{rms}}$, compared to $191.4 \mathrm{~V}_{\mathrm{rms}}$ for the test result.

The load test results used in this analysis were obtained by current variation from 0 to $150 \mathrm{~A}$ at a fixed speed of $3300 \mathrm{rpm}$. During the test, data were recorded for variations in motor input and output characteristics, input current, input voltage, output torque, and power factor. Fig. 14 shows the contour of input current on the $\mathrm{d}-\mathrm{q}$ plane in case of the highest excited condition. In case of the lowest excited condition, the input current varied from 0 to $125 \mathrm{~A}$.

An input voltage vector can be determined from the computed inductance values along with the input current vector using (6). Then, the power-factor is obtained by the angle between input current and computed voltage vectors.

The computed power-factor values are illustrated in Fig. 15. The output torque calculation considering the crosscoupled saturation more accurately modeled the experimental torque in the motor as shown in Figs. 16 and 17. The computed torque values are obtained by using (5). These two graphs suggest that the cross-coupled saturation has more influence at higher current conditions which have more negative d-axis current values. Also, the difference between the calculated values with and without the crosscoupled inductance increase in the case of the lowest excited conditions.

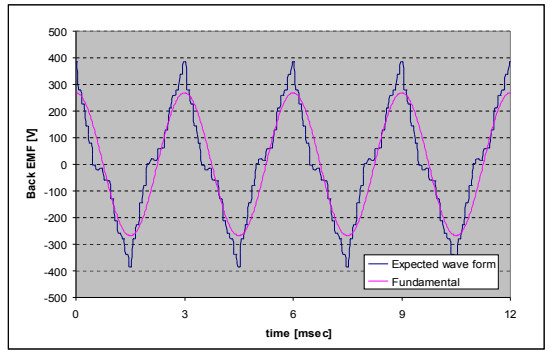

Fig. 12. Simulation results of unloaded phase back-emf waveforms of the highest excited condition at $5000 \mathrm{rpm}$.

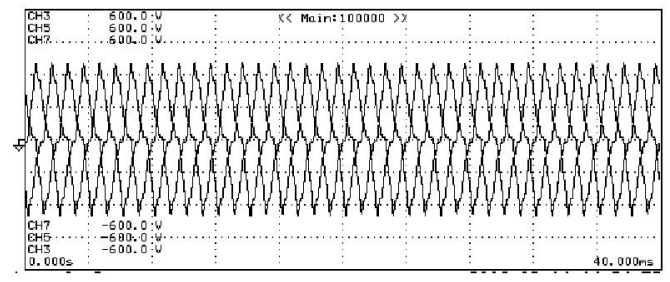

Fig. 13. Test results of unloaded phase back-emf waveforms of the highest excited condition at $5000 \mathrm{rpm}$

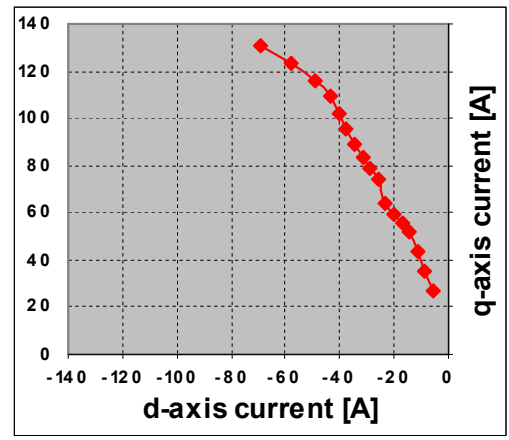

Fig. 14. Input current contour on d-q current plane in case of the highest excited condition.

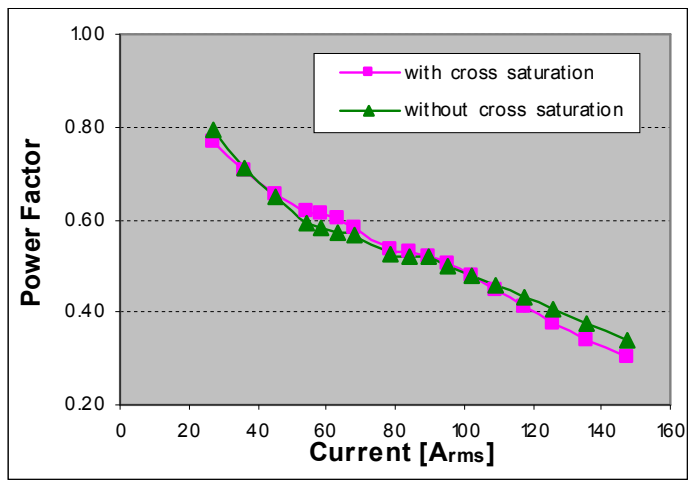

Fig. 15. Computed power factors vs.input current values.

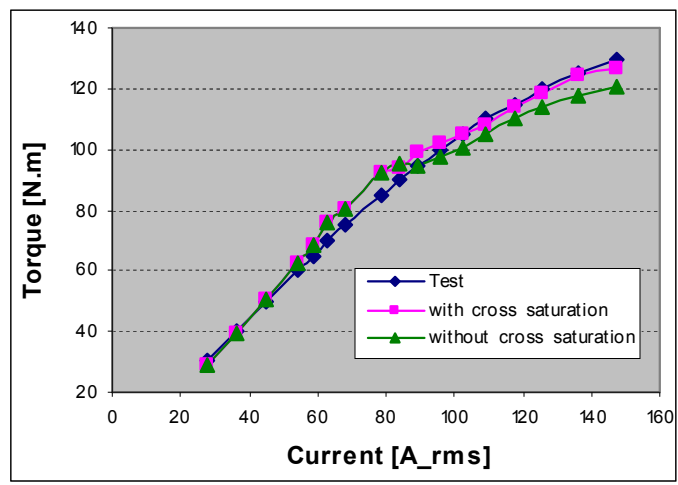

Fig. 16. Comparison of output torque values vs.input current values in case of the highest excited condition.

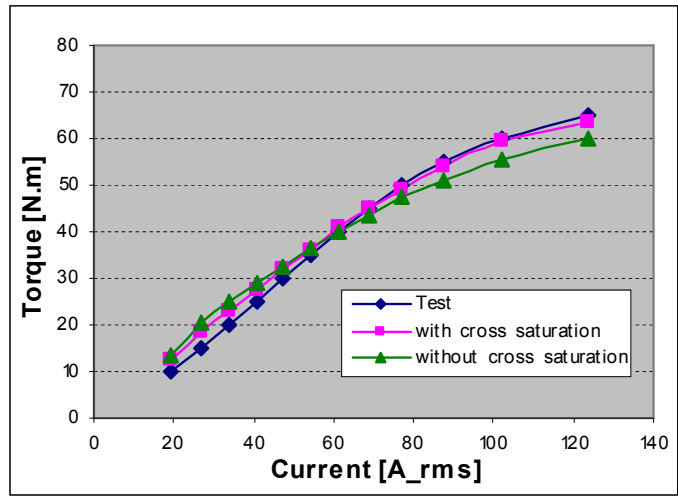

Fig. 17. Comparison of output torque values vs.input current values in case of the lowest excited condition. 
These results show that a less saturated synchronous machine is more easily affected by the cross-coupled saturation. Figs. 16 and 17 also suggest that (5) can be used as the dynamic model of an IPMSM for the controller to develop a better control strategy.

\section{CONCLUSIONS}

The conventional two-axis IPMSM model was modified to include the cross-saturation effect by adding the crosscoupled inductance terms $L_{d q}$ and $L_{q d}$. By the advantage of the excited structure of the experimental IPMSM, the analyzing works were performed under two conditions, the highest and lowest excited conditions. Therefore, it is possible to investigate the cross-saturation effect when a machine has higher magnetic flux from its rotor. The following is a summary of conclusions that may be drawn from this work:

1. Considering cross saturation of an IPMSM offers more accurate expected values of motor parameters in output torque calculation, especially when negative daxis current is high.

2. A less saturated synchronous machine could be more affected by the cross-coupled saturation effect.

3. Both cross-coupled inductances, $L_{q d}$ and $L_{d q}$, are mainly governed by d-axis current rather than q-axis current.

4. The modified torque equation, (5), can be used for the dynamic model of an IPMSM for developing a better control model or control strategy.

5. It is possible that the brushless field excitation structure has a common magnetic flux path on both dand q-axis, and as a result, the reluctance torque of the machine could be reduced.

\section{REFERENCES}

[1] T. J. E. Miller, Brushless Permanent-Magnet and Reluctance Motor Drives, London, Clarendon Press, 1989.
[2] I. Boldea, S. A. Nasar, Electric Machine Dynamics, New York, Macmillan Publishing Company, 1986.

[3] M. A. Rahman, P. Zhou, "Analysis of Brushless Permanent Magnet Synchronous Motors," IEEE Transactions on Industrial Electronics, vol. 43, no. 2, 1996, pp. 256-267.

[4] J. N. Chiasson, Modeling and High Performance Control of Electric Machines, Hoboken, John Wiley \& Sons, 2005.

[5] G. H. Kang, J. P. Hong, G. T. Kim, J. W. Park, "Improved Parameter Modeling of Interior Permanent Magnet Synchronous Motors Based on Finite Element Analysis," IEEE Transactions on Magnetics, vol. 36, no. 4, 2000, pp. 1867-1870.

[6] B. Stumberger, G. Stumberger, D. Dolinar, A. Hamler, M. Trlep, "Evaluation of Saturation and Cross-Magnetization Effects in Interior Permanent-Magnet Synchronous Motor," IEEE Transactions on Industry Applications, vol. 39, no. 5, 2003, pp. $1264-1271$

[7] T. J. E. Miller, M. Popescu, C. Cossar, and M. McGilp, "Performance Estimation of Interior Permanent-Magnet Brushless Motors Using the Voltage-Driven Flux-MMF Diagram," IEEE Transactions on Magnetics, vol. 42, no. 7, 2006, pp. 1867-1872.

[8] E. Levi and V. A. Levi, "Impact of Dynamic Cross-Saturation on Accuracy of Saturated Synchronous Machine Models," IEEE Transactions on Energy Conversion, vol. 15, no. 2, 2000, pp. 224230.

[9] L. Chedot and G. Friedrich, "A Cross Saturation Model for Interior Permanent Magnet Synchronous Machine. Application to a StarterGenerator," IEEE Industry Application Society Annual Meeting, Oct. 3-7, 2004, Seattle, Washington, pp. 64-70.

[10] N. Bianchi, S. Bolognani, and M. Zigliotto, "Design Hints of an IPM Synchronous Motor for an Effective Position Sensorless Control," IEEE Power Electronics Specialists Conference, 2005, pp. $1560-1566$.

[11] N. Bianchi and S. Bolognani, "Influence of Rotor Geometry of an IPM Motor on Sensorless Control Feasibility," IEEE Transactions on Industry Applications, vol. 43, no. 1, 2007, pp. 87-96.

[12] J. S. Hsu, T. A. Burress, S. T. Lee, R. H. Wiles, C. L. Coomer, J. W. McKeever, and D. J. Adams, "16,000-rpm Interior Permanent Magnet Reluctance Machine with Brushless Field Excitation," IEEE Industry Applications Society Annual Meeting, Oct. 5-9, 2008, Edmonton, Canada, 5 pages.

[13] J. S. Hsu, Seong-Taek Lee, and L. M. Tolbert, "High-Strength Undiffused Brushless (HSUB) Machine," IEEE Industry Applications Society Annual Meeting, Oct. 5-9, 2008, Edmonton, Canada, 8 pages.

[14] J. S. Hsu, T. A. Burress, S. T. Lee, R. H. Wiles, C. L. Coomer, J. W. McKeever, and D. J. Adams, "16,000-rpm Interior Permanent Magnet Reluctance Machine with Brushless Field Excitation," ORNL/TM-2007/167, Oak Ridge National Laboratory, Oak Ridge, Tennessee, 2007. 